\title{
Clinical Reasoning: A 42-Year-Old Woman With Mysterious Monocytic Meningitis
}

Meghan E. Nothem, DO, Ryan M. Lee, MD, PhD, Jonathan M. Katz, BS, Paul A. Bergl, MD, and Ahmed Z. Obeidat, MD, PhD

Neurology ${ }^{\circledR}$ 2021;97:449-454. doi:10.1212/WNL.0000000000012155
Correspondence

Dr. Nothem

mnothem@mcw.edu

\section{Section 1}

A 42-year-old woman with a history of migraine headaches and no other significant past medical history presented with daily headaches, cervicalgia, and nausea over a period of 3 weeks. These headaches were similar in severity to those that she had previously experienced. Presumptive migraine treatment was administered and she was released home. Three days later, her symptoms worsened and she developed double vision, unsteady gait, and right-sided hearing loss. She reported no fever or weight loss. Residing in the upper Midwest, her leisure activities included hunting pheasant, deer, and duck, and she regularly cooked and ate wild game. She had traveled periodically to a southwestern state in the months prior to presentation. In the year preceding the current illness, she had experienced multiple tick bites and reported that she had Lyme disease as a teenager.

Physical examination showed a somnolent patient who required tactile stimulation to rouse and who was not oriented to time or situation. Her vital signs were unremarkable with afebrile temperature at $98.2^{\circ} \mathrm{F}$. Pupils were reactive, but she displayed impaired left eye adduction, supraduction, and to a lesser degree infraduction with impaired right eye abduction. She also had bilateral facial muscle weakness, impaired hearing bilaterally, hypophonic speech, dysphagia (later confirmed by a fluoroscopic swallow study), and impaired palate elevation. She had motor weakness in bilateral lower extremities, and to a lesser extent in upper extremities. Muscle weakness distribution involved flexors in lower extremities graded at $3 / 5$ and extensors at $4 / 5$ as opposed to upper extremities at $5 / 5$ in flexors and 4/5 in extensor groups. Truncal ataxia was present. She had no rash, lymphadenopathy, or evidence of inflammatory arthritis, and the remainder of her examination was unremarkable. Initial laboratory results were unremarkable other than elevated erythrocyte sediment rate at 19 seconds but normal C-reactive protein $(<0.29 \mathrm{mg} / \mathrm{L})$. Multiple CT scans of the head during the first 3 weeks of treatment showed no acute abnormalities including no evidence of hemorrhage, and CSF testing revealed elevated protein of $146.1 \mathrm{mg} / \mathrm{dL}$ (normal range $15-45 \mathrm{mg} / \mathrm{dL}$ ), low glucose of $<10 \mathrm{mg} / \mathrm{dL}$ (serum glucose level was $106 \mathrm{mg} / \mathrm{dL}$ ), and increased nucleated cells to 518/UL (normal 0 to 8/ UL) with $86 \%$ monocytes, $10 \%$ lymphocytes, and $4 \%$ neutrophils. Gram stain and microbial cultures were negative and no opening pressure was documented.

\section{Questions for Consideration:}

1. What is the possible localization based on the patient's presenting symptoms?

2. What diagnoses are supported by CSF monocytosis and low CSF glucose (hypoglycorrhachia)?

GO TO SECTION 2 


\section{Section 2}

The patient's symptoms and signs likely suggest multiple cranial nerve or multilevel brainstem involvement and cannot be localized to a single lesion. Left eye impaired adduction, supraduction, and infraduction suggest left cranial nerve III palsy. The impaired abduction of the right eye suggests right cranial nerve VI palsy. Facial weakness suggests involvement of bilateral cranial nerve VII; impaired hearing suggests bilateral cranial nerve VIII palsy. Hypophonic speech and impaired soft palate elevation suggest involvement of cranial nerves IX and X. Corticobulbar tracts involvement is also possible at the level of midbrain or higher. The pattern of motor weakness (predominant extensor weakness in upper extremities and flexor weakness in lower extremities) suggests corticospinal tracts involvement. Based on the extent of cranial nerves involved, a large brainstem lesion would be unlikely with preserved consciousness, (i.e., sparing the majority of the reticular activating system or network).

The combination of CSF monocytosis and low CSF glucose (hypoglycorrhachia) suggested infection, autoimmune/ inflammatory/granulomatous disease, or a neoplastic disorder of the CNS. Hypoglycorrhachia is seen in CNS infections, including bacterial, fungal, and occasionally viral. ${ }^{1}$ In a singlecenter retrospective cohort study, hypoglycorrhachia was most commonly due to bacterial infections, particularly among patients with previous neurosurgical procedures, and fungal meningitis, especially among immunocompromised hosts. ${ }^{1}$ However, in immunocompetent patients, noninfectious etiologies were more common and included neurosarcoidosis, leukemia, CNS lymphoma, and leptomeningeal carcinomatosis. ${ }^{1}$

The differential diagnosis for CSF monocytosis is not well defined. Monocytes are critical to innate immunity, and peripheral monocytosis is a nonspecific marker generally reflecting the presence of chronic or indolent infections, autoimmune disorders, hematologic malignancies, or solid tumors. ${ }^{2}$ Their abundance in the CSF would suggest a similarly wide range of etiologies.

\section{Questions for Consideration:}

1. What further testing or workup would you perform in this patient?

2. Do your differential diagnoses favor infectious or noninfectious etiologies? 


\section{Section 3}

Brain MRI demonstrated abnormal contrast enhancement of cranial nerves III, V, VII, VIII, X, and XI bilaterally and bony thickening of the occipital skull and adjacent dura across the right tentorium and into the posterior fossa (figure, $\mathrm{A}-\mathrm{C}$ ); the latter was considered suggestive of a meningioma. Meningeal contrast enhancement of the entire spine was also observed (figure, D-F). As the patient's symptoms seemingly improved on antimicrobial therapy including vancomycin, ceftriaxone, and acyclovir, she was discharged home on ceftriaxone for possible neuroborreliosis due to history of multiple tick bites. Three days following discharge, her symptoms worsened. A repeat lumbar puncture (LP) demonstrated an opening pressure of $23 \mathrm{~cm}$ of water, elevated protein of $230.9 \mathrm{mg} / \mathrm{dL}$, glucose $<10 \mathrm{mg} / \mathrm{dL}$, and 703/UL nucleated cells with $88 \%$ monocytes, $7 \%$ lymphocytes, and 5\% neutrophils. CSF venereal disease research laboratory, serum $\beta$-D-glucan, and serologic studies for syphilis were negative.

The patient's presentation progressed to include nonreactive left pupil, mydriasis with ptosis, leftward gaze palsy, and dysarthria. Her mental status declined, and she underwent a third LP, notable for an opening pressure of $44 \mathrm{~cm}$ of water with persistent CSF monocytosis and hypoglycorrhachia. CSF flow cytometry was without evidence of malignant cells or lymphoma. An external ventricular drain was placed to alleviate increased intracranial pressure, which was later converted to a ventriculoperitoneal shunt.

Due to the hypoglycorrhachia and CSF monocytosis, extensive immunologic and infectious studies were performed during the patient's hospitalizations. These studies were unrevealing and included a negative CT of the chest, abdomen, and pelvis for sarcoidosis, blood cultures, HIV testing,

Figure Diffuse Leptomeningeal Enhancement of Multiple Intracranial Areas and Spinal Cord Along With Worsening of Intracranial Disease and Spinal Cord Hypermetabolism

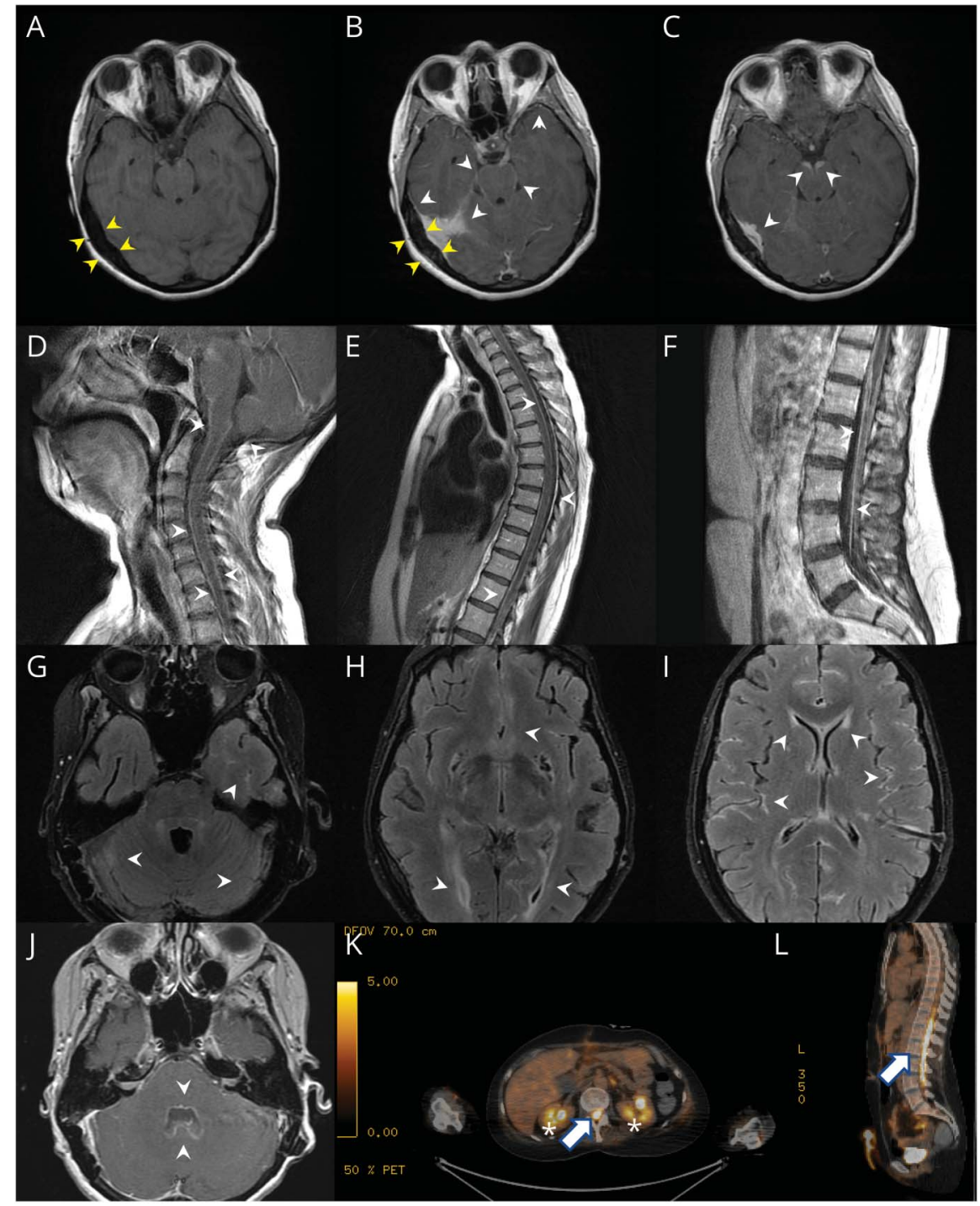

(A) Axial T1 shows no intracranial abnormalities, but demonstrates bony thickening of the right occipital skull (highlighted as yellow arrowheads). (B) Axial T1 postcontrast shows diffuse leptomeningeal and focal parenchymal enhancement. (C) T1 postcontrast shows bilateral anterior midbrain enhancement (arrowheads). (D-F) T1 postcontrast diffuse meningeal enhancement in (D) cervical, (E) thoracic, and (F) lumbosacral spine. (G-I) Axial T2 fluid-attenuated inversion recovery shows multiple areas of increased signal including thickening of the ependyma surfaces and gyral surfaces (arrowheads). (J) Axial T1 postcontrast shows enhancement of the lining of the fourth ventricle (arrowheads). ( $K, L)$ PET scan shows increased uptake in the lower thoracic spine, $(\mathrm{K})$ axial and (L) sagittal. Kidney uptake provided as a reference (asterisks). 
CSF angiotensin-converting enzyme levels, serologic infectious studies (coccidiomycosis, toxoplasmosis, brucellosis, Lyme disease, syphilis, tuberculosis), autoimmune serologic testing (antinuclear antibodies, anticyclic citrullinated peptide antibodies, antineutrophil cytoplasmic antibodies, rheumatoid factor), urine antigen testing for Histoplasma and Blastomyces, CSF bacterial and fungal cultures, CSF nucleic acid amplification test (Cryptococcus species, herpesviridae, Histoplasma, Blastomyces, and tuberculosis), CSF antibodies (Toxoplasma, Borrelia burgdorferi, human lymphocytic choriomeningitis virus), and CSF immunoglobulin G4 levels. Repeat brain MRI 4 days after the first MRI showed worsening of abnormal fluid-attenuated inversion recovery signal, $\mathrm{T} 1$ postcontrast enhancement, including leptomeningeal structures, and development of ependymal thickening (figure, G-I). Although empiric high-dose glucocorticoids were considered, treatment was postponed until biopsies of the posterior fossa mass and cranial nerve $\mathrm{V}$ were performed. Pathologic examination revealed that the posterior fossa mass was WHO grade I meningioma, and cranial nerve $\mathrm{V}$ showed atypical histiocytic reaction, possibly Erdheim-Chester disease (ECD), a rare multisystem disorder in the form of histiocytosis that often involves the CNS.

Given the concern for a disseminated histiocytosis, the patient underwent nuclear medicine bone scanning, which showed no bony lesions, and PET testing, which had no bony uptake but predictably demonstrated diffuse leptomeningeal hypermetabolic activity in the thoracic and lumbar spine (figure, $\mathrm{K}$ and $\mathrm{L}$ ).

\section{Question for Consideration:}

1. How would you manage the patient at this time?

GO TO SECTION 4 


\section{Section 4}

Although the patient's cranial nerve biopsies and other noninvasive testing could not establish a definitive diagnosis, dexamethasone was initiated for presumed ECD or a related histiocytic disorder. Initially, her mentation, hearing, and diplopia improved. She experienced peritonitis and sepsis secondary to gastric perforation in association with her ventriculoperitoneal shunt, requiring surgical removal and exchange with ventriculopleural shunt.

Despite steroids, the patient experienced progressive neurologic decline with worsening ptosis, ophthalmoplegia, and loss of facial tone. Repeat cranial nerve biopsy was considered too risky and presumably low yield after prolonged exposure to steroids. She was treated empirically for an uncharacterized malignant histiocytic disorder with cladribine $7 \mathrm{mg}$ IV daily for 3 days.
Despite treatment, the patient developed acute hydrocephalus and severe neurologic impairment on day 3 of chemotherapy, which was likely secondary to communicating hydrocephalus with inadequate CSF absorption. An external ventricular drain was emergently placed for brain herniation without subsequent neurologic improvement. Her family ultimately opted to transition to comfort measures.

Autopsy showed CNS histiocytic sarcoma with diffuse leptomeningeal involvement of inferior frontal lobe, temporal lobes, cerebellum, brainstem, spinal cord, spinal roots, and ventricular system with hydrocephalus, residual meningioma in the posterior occipital dura, and pleuritis with fibrinous adhesions on posterolateral and inferolateral pleural surfaces.

\section{Questions for Consideration:}

1. What are histiocytoses?

2. How well does this case align with classic ECD? 


\section{Section 5}

Histiocytoses are rare disorders that span a variety of clinical diseases that are histologically similar. In general, histiocytoses are characterized by accumulation of monocyte-derived cells, such as macrophages and dendritic cells, in end organs. ${ }^{3} \mathrm{ECD}$ is a rare form of non-Langerhans cell histiocytosis that may affect multiple organ systems but almost uniformly causes osteosclerotic bony lesions. ${ }^{4}$ Other systemic findings include periaortic encasement, cardiac masses and pseudotumors, diabetes insipidus, retro-orbital inflammation and exophthalmos, CNS infiltration, and retroperitoneal fibrosis. ${ }^{4}$ Ultimately, the diagnosis hinges on characteristic immunostaining patterns of macrophages and subsequent molecular testing, with BRAF V600E or RAS mutations often detected in biopsies. ${ }^{4,5}$

Histiocytoses that affect the CNS, such as ECD, are typically indolent with slow progression of symptoms. ${ }^{4}$ In this case, the rapid clinical decline despite empiric steroids and an exhaustive evaluation for infection suggested a more sinister and aggressive form of CNS disease. As a subtype of primary CNS lymphoma, primary CNS histiocytic sarcoma (PCNSHS) has been documented only a few dozen times. ${ }^{6,7}$ PCNSHS can present with one or more lesions in the cerebrum, cerebellum, meninges, and spinal cord. Clinical symptoms can range from headache to frank neurologic deficits. ${ }^{6,8}$ Prognosis is generally poor with reported average survival of 19-29 months. ${ }^{6}$ Treatment courses are nonstandardized and have included combinations of surgical resection, radiation, and chemotherapies, as well as interferons, without any successful treatments developed to date., ${ }^{6,8}$

\section{Study Funding}

The authors report no targeted funding.

\section{Disclosure}

The authors have no disclosures to report. Go to Neurology. org/ $\mathrm{N}$ for full disclosures.
Appendix Authors

\begin{tabular}{lll}
\hline Name & Location & Contribution \\
\hline $\begin{array}{l}\text { Meghan E. } \\
\text { Nothem, Do }\end{array}$ & $\begin{array}{l}\text { Medical College of } \\
\text { Wisconsin, } \\
\text { Milwaukee }\end{array}$ & $\begin{array}{l}\text { Concept, drafted and revised the } \\
\text { manuscript, analyzed and } \\
\text { interpreted data }\end{array}$ \\
\hline $\begin{array}{l}\text { Ryan M. Lee, } \\
\text { MD, PhD }\end{array}$ & $\begin{array}{l}\text { Medical College of } \\
\text { Wisconsin, } \\
\text { Milwaukee }\end{array}$ & $\begin{array}{l}\text { Prepared the figure, analyzed and } \\
\text { interpreted data, performed critical } \\
\text { revision of the manuscript for } \\
\text { intellectual content }\end{array}$ \\
$\begin{array}{l}\text { Jonathan M. } \\
\text { Katz, BS }\end{array}$ & $\begin{array}{l}\text { Medical College of } \\
\text { Wisconsin, }\end{array}$ & $\begin{array}{l}\text { Drafted and revised the manuscript, } \\
\text { analyzed and interpreted data }\end{array}$ \\
\hline $\begin{array}{l}\text { Paul A. Bergl, } \\
\text { MD }\end{array}$ & $\begin{array}{l}\text { Medical College of } \\
\text { Wisconsin, } \\
\text { Milwaukee }\end{array}$ & $\begin{array}{l}\text { Drafted and revised the manuscript, } \\
\text { analyzed and interpreted data and } \\
\text { approved all final changes }\end{array}$ \\
$\begin{array}{l}\text { Ahmed Z. } \\
\text { Obeidat, MD, } \\
\text { PhD }\end{array}$ & $\begin{array}{l}\text { Medical College of } \\
\text { Wisconsin, } \\
\text { Milwaukee }\end{array}$ & $\begin{array}{l}\text { Performed critical revision of } \\
\text { the manuscript, analyzed and } \\
\text { interpreted data, prepared } \\
\text { the figure, revised the } \\
\text { manuscript and approved all } \\
\text { final changes }\end{array}$ \\
\hline
\end{tabular}

\section{References}

1. Chow E, Troy SB. The differential diagnosis of hypoglycorrhachia in adult patients. Am J Med Sci. 2014;348(3):186-190.

2. Lynch DT, Hall J, Foucar K. How I investigate monocytosis. Int J Lab Hematol. 2018; 40(2):107-114.

3. Emile JF, Abla O, Fraitag S, et al. Revised classification of histiocytoses and neoplasms of the macrophage-dendritic cell lineages. Blood. 2016;127(22): 2672-2681.

4. Estrada-Veras JI, O'Brien KJ, Boyd LC, et al. The clinical spectrum of ErdheimChester disease: an observational cohort study. Blood Adv. 2017;1(6):357-366.

5. Diamond EL, Dagna L, Hyman DM, et al. Consensus guidelines for the diagnosis and clinical management of Erdheim-Chester disease. Blood. 2014;124(4): 483-492.

6. Ma S, Schild M, Tran D, et al. Primary central nervous system histiocytic sarcoma: a case report and review of literature. Medicine. 2018;97(26):e11271.

7. Zanelli M, Ragazzi M, Marchetti G, et al. Primary histiocytic sarcoma presenting as diffuse leptomeningeal disease: case description and review of the literature. Neuropathology. 2017;37(6):517-525.

8. So H, Kim SA, Yoon DH, et al. Primary histiocytic sarcoma of the central nervous system. Cancer Res Treat. 2015;47(15 suppl):322-328.

\section{Announcing... \\ Child Neurology: A Case-Based Approach Cases From the Neurology ${ }^{\circ}$ Resident \& Fellow Section}

This collaboration between the American Academy of Neurology (AAN) and the Child Neurology Society (CNS) represents a collection of reprinted cases from the past 15 years from the Neurology Resident \& Fellow Section.

An invaluable resource for both adult and pediatric neurologists and trainees! FREE download: NPub.org/cnbook 


\section{Neurology}

Clinical Reasoning: A 42-Year-Old Woman With Mysterious Monocytic Meningitis Meghan E. Nothem, Ryan M. Lee, Jonathan M. Katz, et al.

Neurology 2021;97;449-454 Published Online before print May 4, 2021

DOI 10.1212/WNL.0000000000012155

This information is current as of May 4, 2021

Updated Information \& Services

References

Subspecialty Collections

Permissions \& Licensing

Reprints including high resolution figures, can be found at: http://n.neurology.org/content/97/9/449.full

This article cites 8 articles, 3 of which you can access for free at: http://n.neurology.org/content/97/9/449.full\#ref-list-1

This article, along with others on similar topics, appears in the following collection(s):

Meningitis

http://n.neurology.org/cgi/collection/meningitis

Information about reproducing this article in parts (figures,tables) or in its entirety can be found online at:

http://www.neurology.org/about/about_the_journal\#permissions

Information about ordering reprints can be found online:

http://n.neurology.org/subscribers/advertise

Neurology ${ }^{\circledR}$ is the official journal of the American Academy of Neurology. Published continuously since 1951, it is now a weekly with 48 issues per year. Copyright (C 2021 American Academy of Neurology. All rights reserved. Print ISSN: 0028-3878. Online ISSN: 1526-632X.

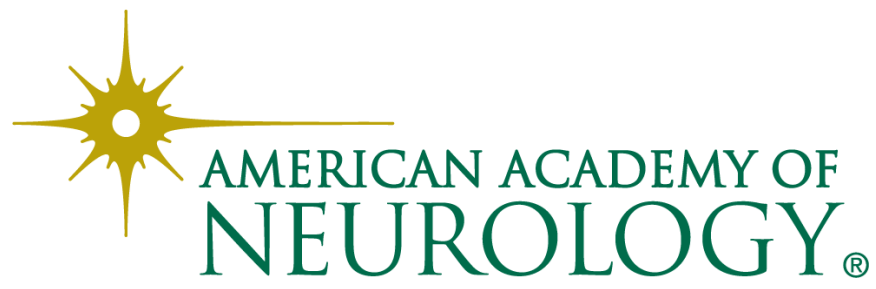

